\title{
Synthesis, Characterization and Antimicrobial Activity of New 2-Phenylquinoline-4(3H)-one Derivatives
}

\author{
ALI HAMMADI SAMIR* \\ Department of Chemistry, College of Education for Pure Science-Ibn Al-Haitham, \\ Baghdad University, Baghdad, Iraq. \\ ${ }^{*}$ Corresponding author E-mail: dr.mohammd08@ gmail.com
}

http://dx.doi.org/10.13005/ojc/330344

(Received: April 21, 2017; Accepted: May 29, 2017)

\begin{abstract}
Quinazolinones is an important chemical synthesis with different physiological significance and pharmacological utility. Reaction of anthranilic acid with benzoyl chloride in pyridine yielded 2-phenyl$4 \mathrm{H}$-benzo[d][1,3]oxazin-4-one, which on condensation reaction with the tryptophan in glacial acetic acid afforded 3-(1H-indol-3-yl)-2-(4-oxo-2-phenylquinazolin-3(4H)-yl) propanoic acid (2). Treatment of compound (2) with thionyl chloride produced 3-(1H-indol-3-yl)-2-(4-oxo-2-phenylquinazolin-3(4H)-yl) propanoyl chloride (3).Condensation of compound (3) with hydrazine hydrate gave $3-(1 \mathrm{H}$-indol-3-yl)2-(4-oxo-2-phenylquinazolin-3(4H)-yl) propanehydrazide (4). Condensation of compound (4) with ethyl aceto acetate in glacial acetic acid yielded 3-(3-(1H-indol-3-yl)-1-(3-methyl-5-oxo-4,5-dihydro- $1 \mathrm{H}$ pyrazol-1-yl)-1-oxopropan-2-yl)-2-phenylquinazolin-4(3H)-one (5). The reaction of compound (4) with carbon disulfide and sodium hydroxide yielded3- $(2-(1 \mathrm{H}$-indol-3-yl)-1-(5-mercapto-1,3,4-oxadiazol-2$\mathrm{yl}$ ) ethyl)-2-phenylquinazolin-4(3H)-one (6).Condensation of compound (6) with hydrazine hydrate afforded 2-hydrazinyl-5- (2-(1H-indol-3-yl) ethyl)-2-phenylquinazolin-4(3H)-one(7). Compound (8) 2-(3-(1H-indol-3-yl)-2-(4-oxo-2-phenylquinazolin-3(4H)-yl)propanoyl)-2,3-dihydrophthalazine-1,4dione was synthesized by condensing compound (4) with phthalic anhydride in glacial acetic acid. When compound (4) was reacted with different aromatic aldehydes in abs. ethanol afforded different substituted (9a-d).Moreover, N-(1,5-dioxo-3-substituted-1,5-dihydrobenzo[e][1,3] oxazepin-4(3H)$\mathrm{yl})-3-(1 \mathrm{H}$-indol-3-yl)-2-(4-oxo-2-phenylquinazolin-3(4H)-yl) propanamide $(10 \mathrm{a}, \mathrm{b})$ were prepared from the cyclic condensation of Schiff bases compounds with phthalic anhydride. The structures of newly synthesized compounds were characterized by m.p., TLC, FTIR and ${ }^{1} \mathrm{H},{ }^{13} \mathrm{C}-\mathrm{NMR}$ spectral analysis. The antimicrobial activity of the synthesized phenylquinazoline on two kinds of bacteria namely, staphylococcus aureous and Escherichia coli was investigated.
\end{abstract}

keywords: Phenylquinazoline, oxadiazole, triazole, pyrazole, oxazepin

\section{INTRODUCTION}

Quinazolinone is one of the flourishing compounds in pharmaceutical fields. Quinazolines and its derivatives represent one of the most active classes of compounds. Medically it has been exhibited various activites as antibacterial $^{1,2}$, cytotoxic $^{3}$, analgesic , anti-inflammatory ${ }^{4}$, 
anticonvusant ${ }^{5}$, antitubercular ${ }^{6,7}$, anticancer ${ }^{8}$, and antioxidant ${ }^{9}$, anti-HIV ${ }^{10}$, antitumour ${ }^{11}$, and antimicrobial ${ }^{12}$.Quinazolinones derivatives were exhibit substantial in treating of leukemia than the common drugs $^{13}$. Recent studies demonstrated the significant effect of quinazolinones derivatives via breast cancer in vitro study ${ }^{14-16}$.

Aim of the present study is to synthesis a new phenyl quinazoline derivatives as antibacterial agents.

\section{MATERIAL AND METHOD}

\section{Chemistry}

Melting points were determined using electrothermal melting point apparatus. A SHMADZUFT-IR-8400 spectrometer was used to record the Infrared spectra atyrhe miss $\mathrm{KBr}$ disc. All ${ }^{1} \mathrm{H},{ }^{13} \mathrm{C}$-NMR spectra measurement were made at Al-Albayt University, Jordan and Cairo University, Egypt on a Bruker $300 \mathrm{MHz}$ and Avance III HD spectrometers using DMSO- $\mathrm{d}_{6}$ a solvent and TMS as internal reference. The progress of the reaction was monitored by TLC using aluminum silica gel plates. Grade solvent and reagents were purchased from commercial suppliers.

\section{2-phenyl-4H-benzo[d][1,3] oxazin-4-one 1}

$0.01 \mathrm{~mol}$. of $\mathrm{C}_{7} \mathrm{H}_{5} \mathrm{OCl}$ was gradually added to a $30 \mathrm{ml}$ solution of $3.33 \times 10^{-4} \mathrm{M}$ of anthranilic acid in pyridine with continuous stirring at about $15 \mathrm{C}$ for $30 \mathrm{~min}$. The formed product was separated while the reaction mixture stirred for 3 hours room temperature. Finally, apale-yellow solid was yielded upon the addition of $15 \mathrm{ml}$. of $10 \% \mathrm{NaHCO}_{3}$ was added to the solution. The formed precipitate was filtered off and washed with distilled water, dried and ethanol was used for recrystallization. Yield (68\%), m.p. (118-120) $\mathrm{C}^{17}$.

Synthesis of 3-(1H-indol-3-yl)-2-(4-oxo-2phenylquinazolin-3(4H)-yl) propanoicacid 2

(0.001mol.) of 2-phenyl-4H-benzo[d][1,3] oxazin-4-one was mixed with tryptophan in $15 \mathrm{ml}$ of glacial acetic acid. The mixture was refluxed for (3-4) hr., followed by the addition of $(25 \mathrm{ml})$ of Icy distilled water. The product was separated off by filtration and washed with distilled water, the dried. Recrystallization of the obtained product was carried out from ethanol. Yield (70\%), m.p. (165-167) $\mathrm{C}^{18}$.
(1 H-indol-3-yl)-2-(4-oxo-2-phenylquinazolin$3(4 \mathrm{H})-\mathrm{yl})$ propanoylchloride3

A solution of compound 2 (0.01 mol.) and $\mathrm{SOCl}_{2}(2 \mathrm{ml}$.) in (20 ml.) benzene(dry) was refluxed for $4 \mathrm{hr}$. Crystals of the product were obtained by removing the excess of thionyl chloride and benzene under vacuum. yield (75\%), m.p. (158-160) C ${ }^{19}$.

3-(1H-indol-3-yl)-2-(4-oxo-2-phenylquinazolin$3(4 \mathrm{H})-y l)$ propanehydrazide (4)

0.01 mol.of compound 3was mixed with $80 \% \mathrm{~N}_{2} \mathrm{H}_{4} \cdot \mathrm{H}_{2} \mathrm{O}$ solution $(0.5 \mathrm{ml}$., $5 \mathrm{mmol}$.) in dry benzene $(10 \mathrm{ml}$.). After refluxing the mixture for five hours, the mixture was let to cool down to room temperature before removing the excess solvent and hydrazine under reduce pressure. The precipitate that obtained was washed with ether, and purified by recrystallized from ethanol. Yield (85\%), m.p. (178-180) $\mathrm{C}^{19}$.

(3-(1 H-indol-3-yl)-1-(3-methyl-5-oxo-4,5dihydro-1H-pyrazol-1-yl)-1-oxopropan-2-yl)phenylquinazolin- $4(3 \mathrm{H})$-one 5

This compound was synthesized by refluxing $(0.01 \mathrm{~mol}$.) of compound 4 and ethyl acetoacetate $(0.01 \mathrm{~mol}$.) in $20 \mathrm{ml}$. glacial acetic acid for $6 \mathrm{hrs}$. After then, the mixture was cooled and $25 \mathrm{ml}$ of icy distilled water was added, the reaction product (compound 5) was filtered out and dried. Yield (80\%), m.p. (221-223) C 20 .

3-(2-(1 H-indol-3-yl)-1-(5-mercapto-1,3,4oxadiazole-2-yl)ethyl)-2- phenylquinazolin4(3H)-one 6

Twenty milliliters of ethanolic solution of (0.015 mol.) $\mathrm{NaOH}$ was mixed with $(0.01 \mathrm{~mol}$.) of compound 4 with continuous stirring for $15 \mathrm{~min}$. Two milliliters of $\mathrm{CS}_{2}$ was then added before heating the mixture under reflux for $8 \mathrm{hrs}$. After concentrating the mixture, the reaction product was collected by acidification with dilute $\mathrm{HCl}$ solution. The product was then washed with water and recrystallized from ethanol. Yield (76\%), m.p. (229-231) C ${ }^{21}$.

2-hydrazinyl-5- (2-(1H-indol-3-yl) ethyl)-2phenylquinazolin-4(3H)-one 7

To $20 \mathrm{ml}$ of the ethanolic solution of compound $6(0.01 \mathrm{~mol})$, two milliliters of $\mathrm{N}_{2} \mathrm{H}_{4} \cdot \mathrm{H}_{2} \mathrm{O}$ solution were added. After $7 \mathrm{hrs}$ of reflux, the reaction mixture was left to cool down to room temperature. The pure yellow crystals of the product were 
obtained after removing the solvent under vacuum and recrystallization from ethanol. Yield (80\%), m.p. (154-156) C ${ }^{21}$.
2-(3-(1H-indol-3-yl)-2-(4-oxo-2-phenyl quinazolin$3(4 \mathrm{H})-y \mathrm{l})$ propanoyl)-2,3-dihydrophthalazine-1,4dione8

This compound was obtained by refluxing a solution of an equimolar mixture $(0.001 \mathrm{~mol}$.) of compound 4 and phthalic anhydride in glacial acetic

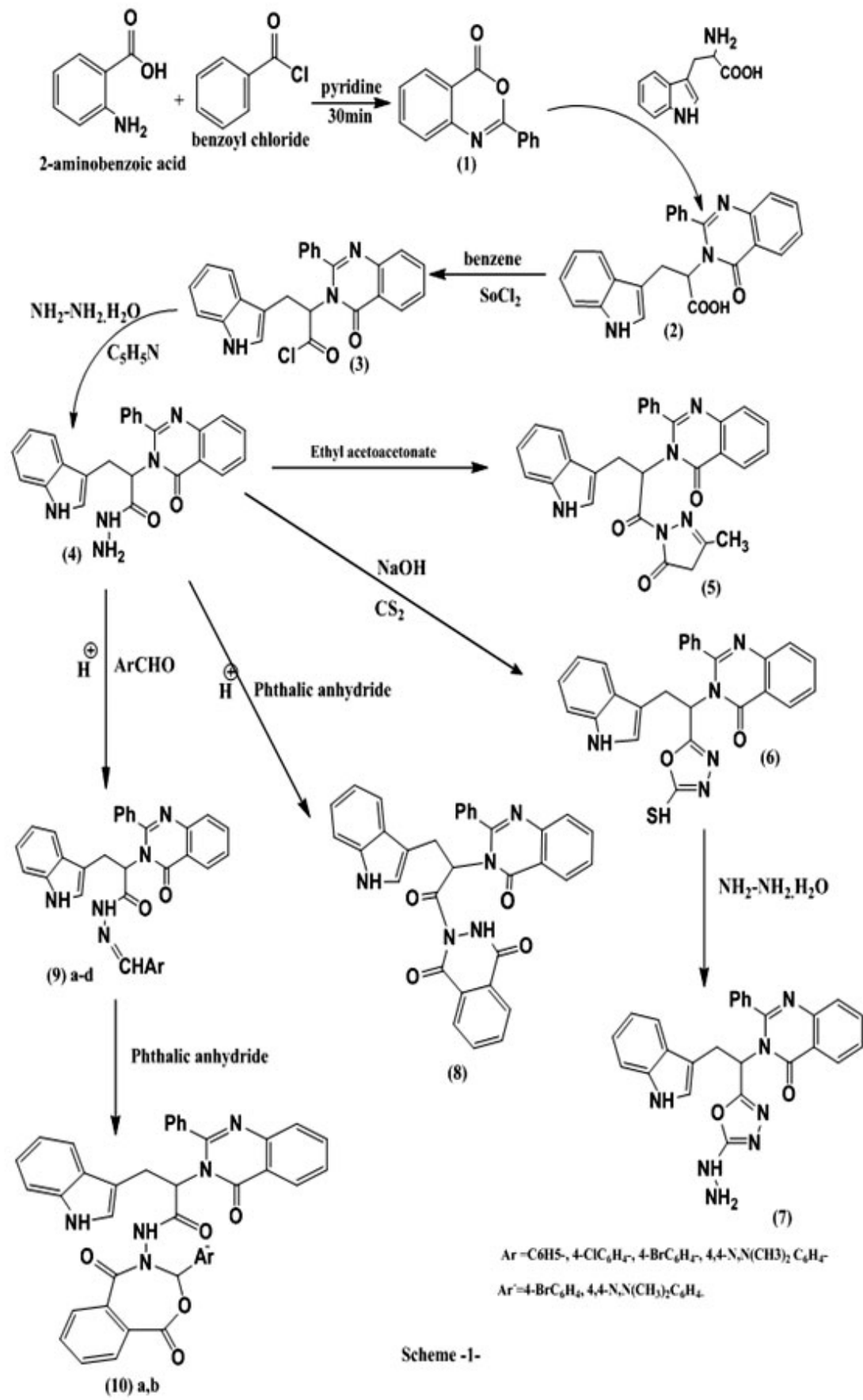

Scheme 1 
acid. After the addition of $20 \mathrm{ml}$. icy distilled water, the product was filtered and dried. Yield (80\%), m.p. $(121-123) C^{22}$.

\section{General method for synthesis of Schiff bases} 9a-d

An equimolar mixture $(0.01 \mathrm{~mol}$.) of and compound 4 with an appropriate aldehydein $(25 \mathrm{ml}$.) of absolute ethanol was refluxed in water bath for $8 \mathrm{hr}$ after the addition of three drops of anhydrous $\mathrm{CH}_{3} \mathrm{COOH}$. The formed product was collected by filtration and dried, after cooling the reaction mixture to room temperature ${ }^{23}$. The molecular formulas, melting points, and the yields of the synthesized compounds are presented in Table (1).

\section{General method for synthesis of oxazepines compounds $10 \mathrm{a}, \mathrm{b}$}

An equimolar mixture $(0.01 \mathrm{~mol}$.) of compounds $9 a, b$ and phthalic anhydride was dissolved in $(10 \mathrm{ml})$ of dry benzene and refluxed in a water bath for $10 \mathrm{hr}$. The solution was then cooled and treated with sodium bicarbonate to formed compound 10a,b. The reaction product i.e.10a,b was separated

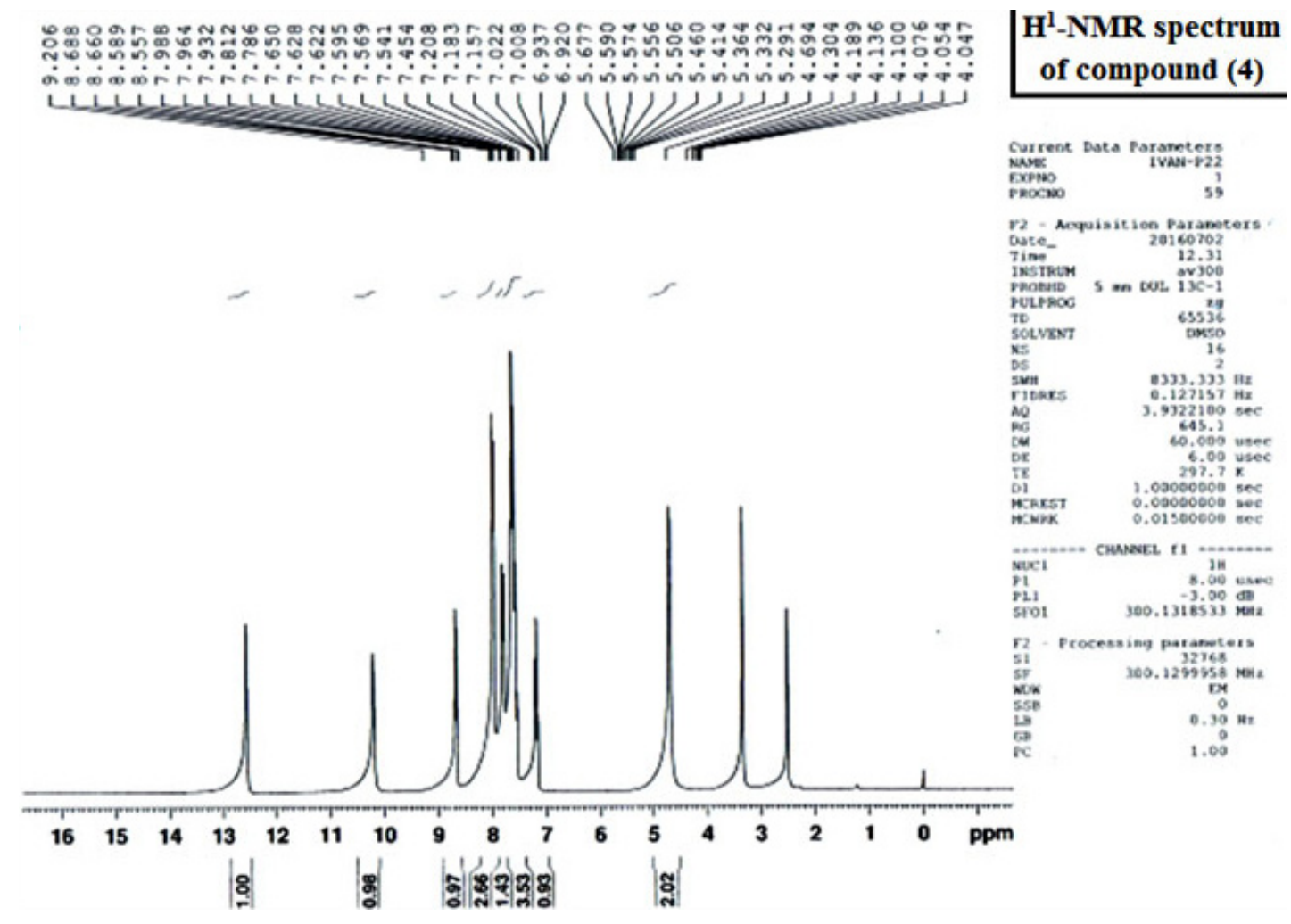

Fig. 1:

Table 1: Physical properties for Schiffs bases and 1,3-oxazepine compounds

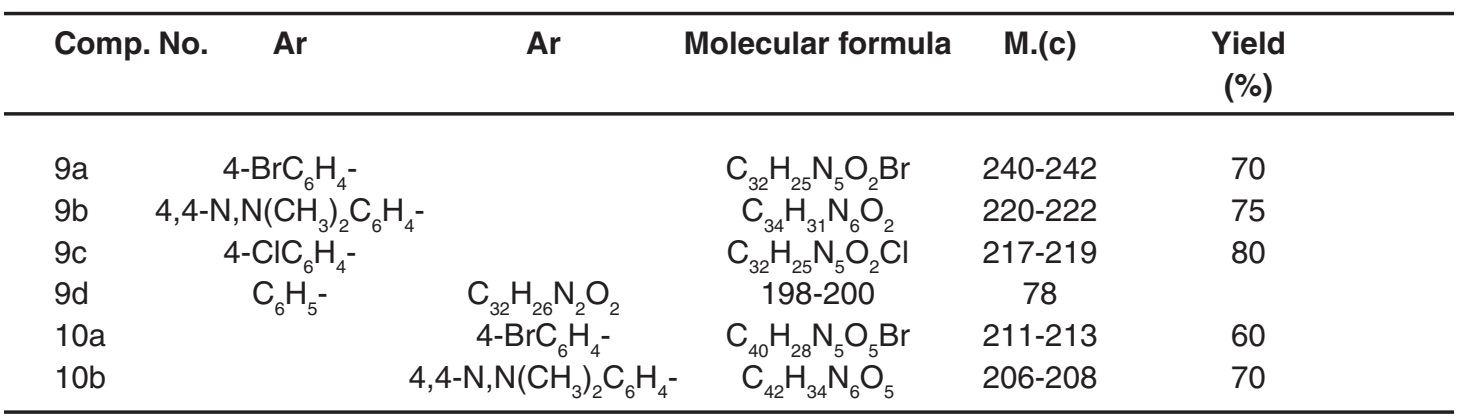


by filtration, dried and recrystallized from ethanol ${ }^{24}$. Table (1) shows the data for compound (10a,b).

\section{Biological Activity}

The antimicrobial activity of the synthesized phenyl quinazoline on two kinds of bacteria namely, staphylococcus aureous and Escherichia coli was investigated. The investigation was carried out via cup method with nutrient agar as a media for bacterial growth using $0.1 \mathrm{ml}$ of DMF as a solvent for all samples. The agar was scoop up from the sterilized cork borer cups and transferred into a bacterially inoculated petri dish. After then, a $0.1 \mathrm{ml}$ aliquot of the solution of the investigated compound was introduced to each dish and the dishes were incubated for $24 \mathrm{hrs}$ at $37^{\circ} \mathrm{C}$.

\section{RESULTS AND DISCUSSION}

\section{Chemistry}

The starting materials 2 -amino-3- $(1 \mathrm{H}-$ indol-3-yl) propanoic acid 2, used in this work was prepared by refluxing of tryptophan with 2-phenyl$4 \mathrm{H}$-benzo[d][1,3]oxazin-4-one (1) in glacial acetic

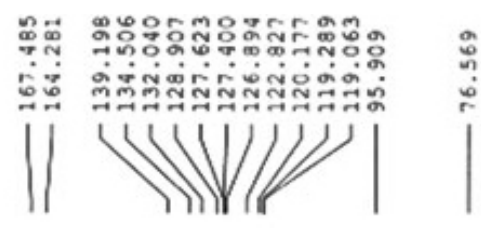

acid. Analytical and spectral data were used to elucidate the structure of compound 2. The FTIR absorption spectrum of the compound displayed bands at $1685 \mathrm{~cm}^{-1}$ for carbonyl of acid, 2500-3200 $\mathrm{cm}^{-1}$ due to $\mathrm{OH}$ group of acid.

Compound 3 was obtained upon treatment of compound2 with thionyl chloride in dry benzene. The presence of acyl chloride group was confirmed using its FTIR spectrum which display a strong absorption band at $1762 \mathrm{~cm}^{-1}$. The reaction of acyl chloride derivative 3 with hydrazide hydrate in refluxing ethanol gave the corresponding hydrazide derivative 4 . The compound shows several bands at $1660 \mathrm{~cm}^{-1}$ which belong to carbonyl of amide, and at $3307,3215 \mathrm{~cm}^{-1}$ for $\mathrm{NH}_{2}$ group. Moreover, its The ${ }^{1} \mathrm{H}-\mathrm{NMR}$ spectrum, fig. (1), shows characteristics chemical shifts, i.e. singlet signals at 5.67, 10.30, and $12.70 \mathrm{ppm}$ which could be related to the protons of $\mathrm{NH}_{2}$ group, proton of $\mathrm{NH}$ group and the proton of $\mathrm{OH}$ group present in two tautomeric forms.

The triplet signal of proton for $\mathrm{CH}$ group at $4.30 \mathrm{ppm}$. Also showed the multiple signal at

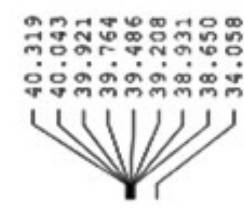

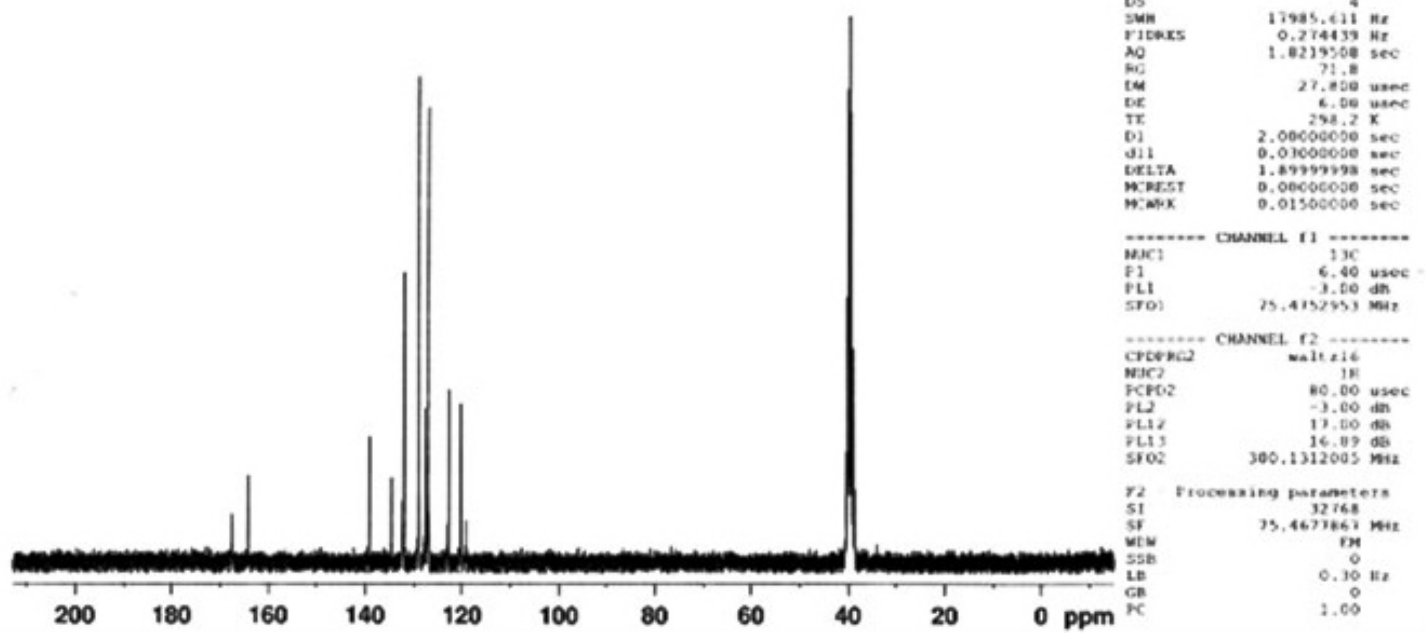

Fig. 2: 
6.92-8.68 ppm for aromatic protons of three benzene rings. The two peaks at at 164 and 167 in the ${ }^{13} \mathrm{C}$ NMR spectrum of compound 4.fig. (2), indicate the presence of two resonating carbonyl groups of amide, while peaks at $(127.40,128.90) p p m$ are due to carbon of $\mathrm{C}=\mathrm{N}$ group.

Compound 4 was treated with ethyl aceto acetate in boiling glacial acetic acid to give compound 5. Bands at 1726, $1678 \mathrm{~cm}^{-1}, 1637 \mathrm{~cm}^{-1}$, and 3309 $\mathrm{cm}^{-1}$ in the FTIR spectrum of compound 5 indicate the presence of $\mathrm{CO}$ amide, $\mathrm{C}=\mathrm{N}, \mathrm{NH}$ groups. The treatment of compound 4 with $\mathrm{CS}_{2}$ in presence of $\mathrm{NaOH}$ yields compound 6. The appearance of two peaks at $(1616,1600) \mathrm{cm}^{-1}$ in the FTIR spectrum of the formed compound could be attributable to the presence of $\mathrm{C}=\mathrm{N}$ of cyclic imine. Moreover, the ${ }^{1} \mathrm{H}$ NMR spectrum of compound 6,fig. (3),exhibited two singlets at $\delta 11.69$ and 11.71 which are specific for $\mathrm{NH}$ and $\mathrm{SH}$ protons, a triplet signal at $\delta 3.45$ for proton of $\mathrm{CH}$ proton, a multiplet at $\delta 7.45-8.69$ related to the aromatic-protons, a singlet at $\delta 8.69$ for $\mathrm{NH}$ of

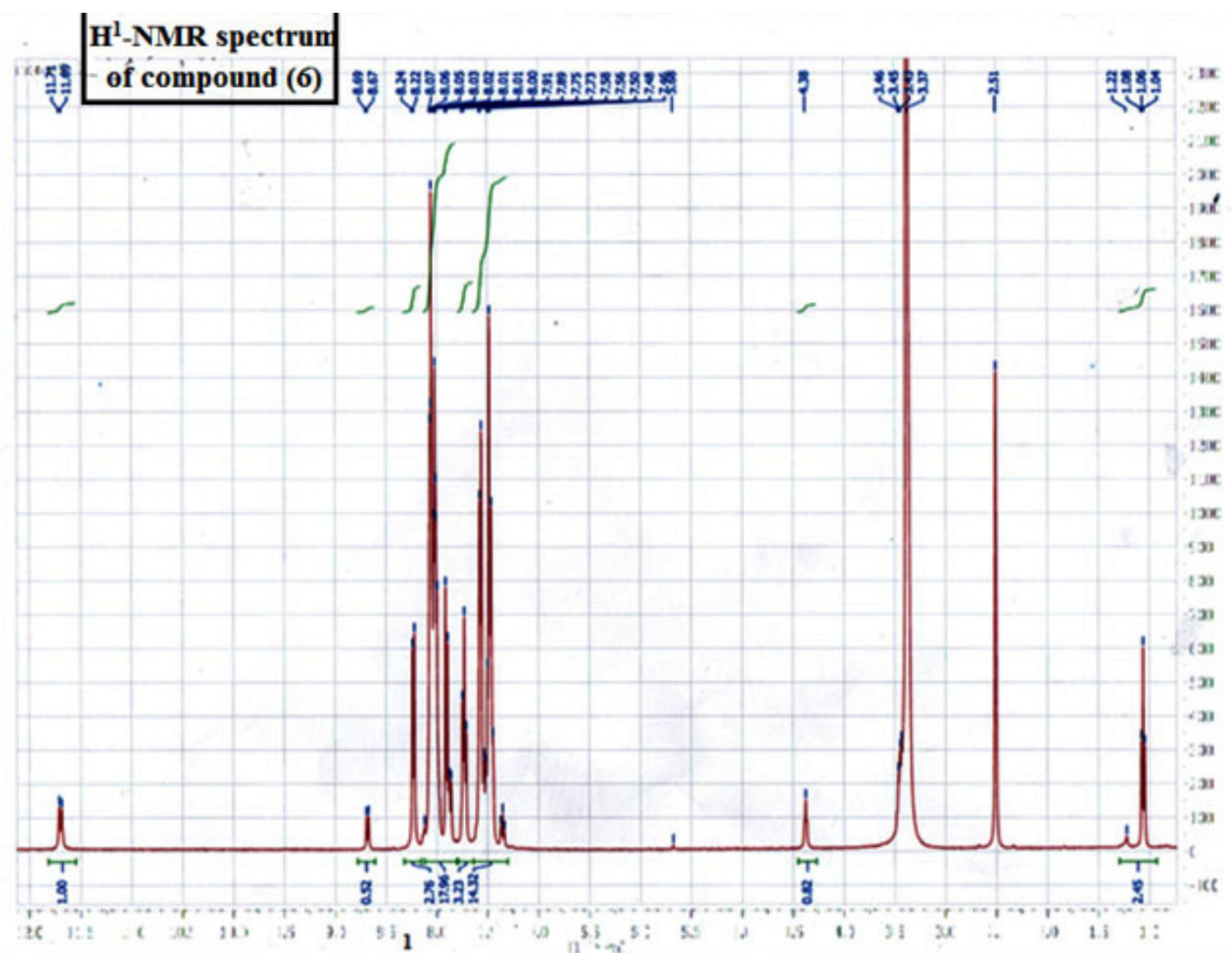

Fig. 3:

Table 2: The FTIR absorption bands for Schiffs bases and 1,3-oxazepine compounds

\begin{tabular}{llllllll}
\hline $\begin{array}{l}\text { Comp. } \\
\text { No }\end{array}$ & N-H & C-H ar. & C-H ali. & $\begin{array}{c}\text { C=O } \\
\text { amide }\end{array}$ & $\begin{array}{c}\text { C=O cyclic } \\
\text { amide }\end{array}$ & $\mathbf{C = N}$ & C=C \\
\hline 9a & 3192 & 3053 & 2988 & 1649 & & 1623 & 1600 \\
9b & 3186 & 3062 & 2970 & 1676 & & 1635 & 1589 \\
9c & 3227 & 3057 & 2960 & 1680 & & 1604 & 1591 \\
9d & 3221 & 3062 & 2983 & 1660 & & 1649 & 1600 \\
10a & 3223 & 3050 & 2966 & 1656 & 1693 & & 1604 \\
10b & 3180 & 3047 & 2970 & 1664 & 1691 & & 1600 \\
\hline
\end{tabular}




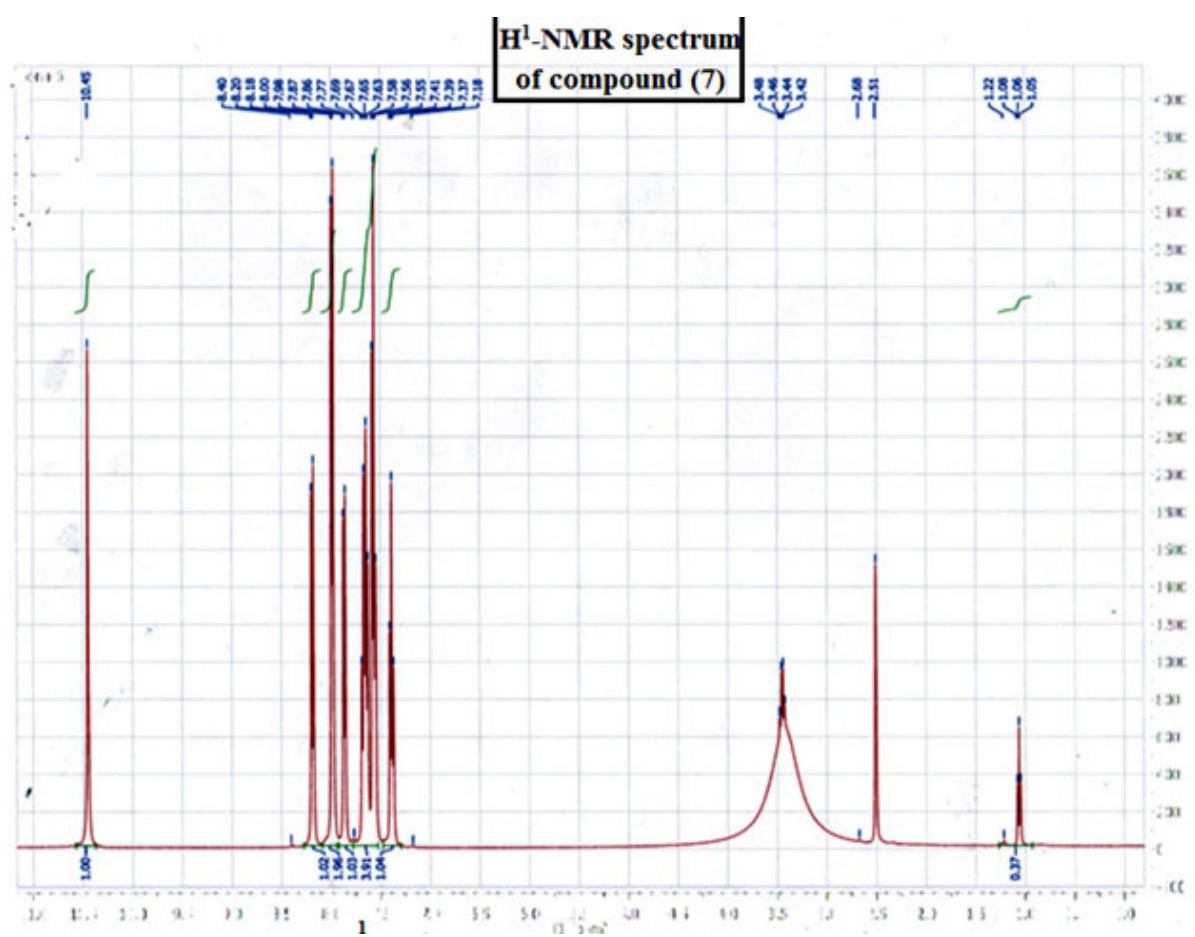

Fig. 4:

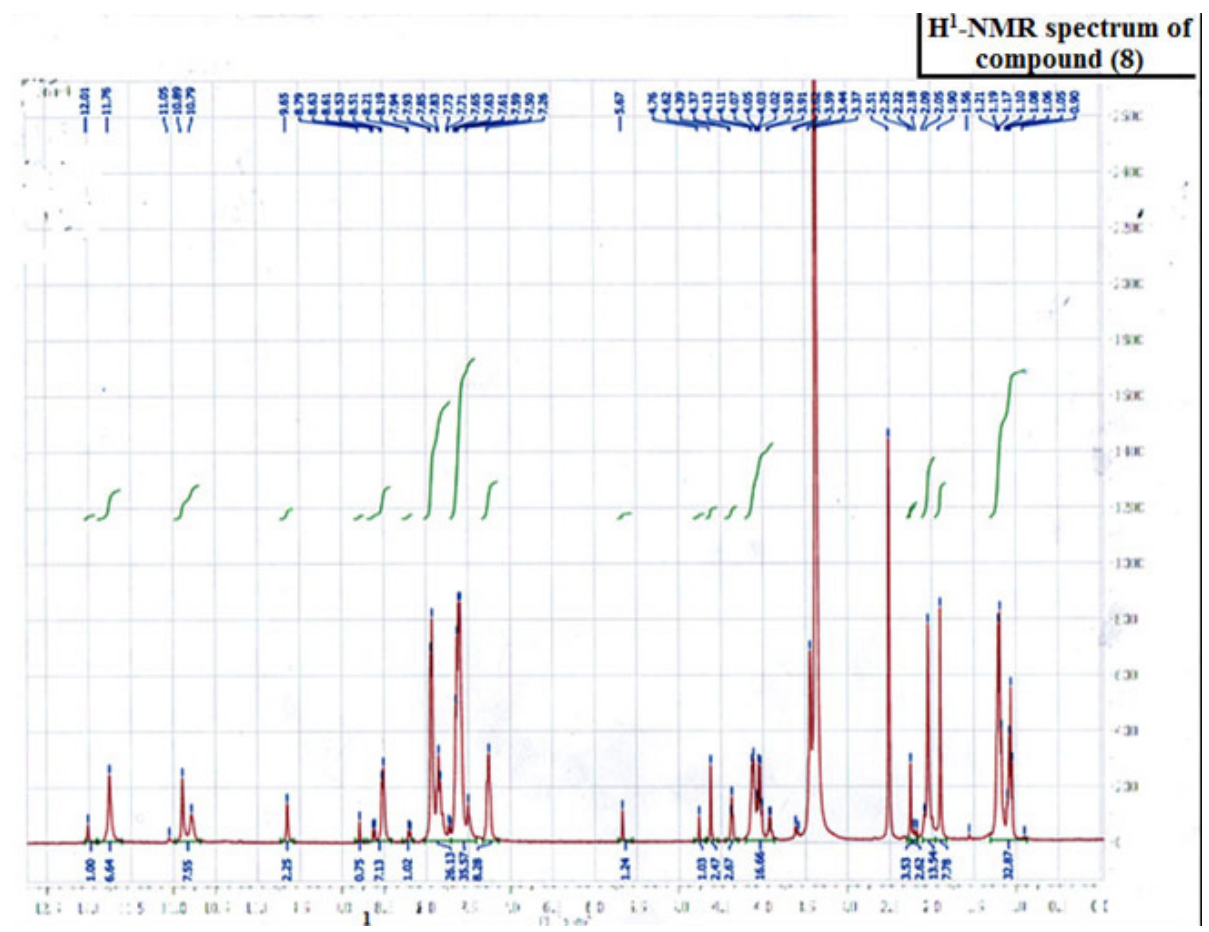

Fig. 5: 


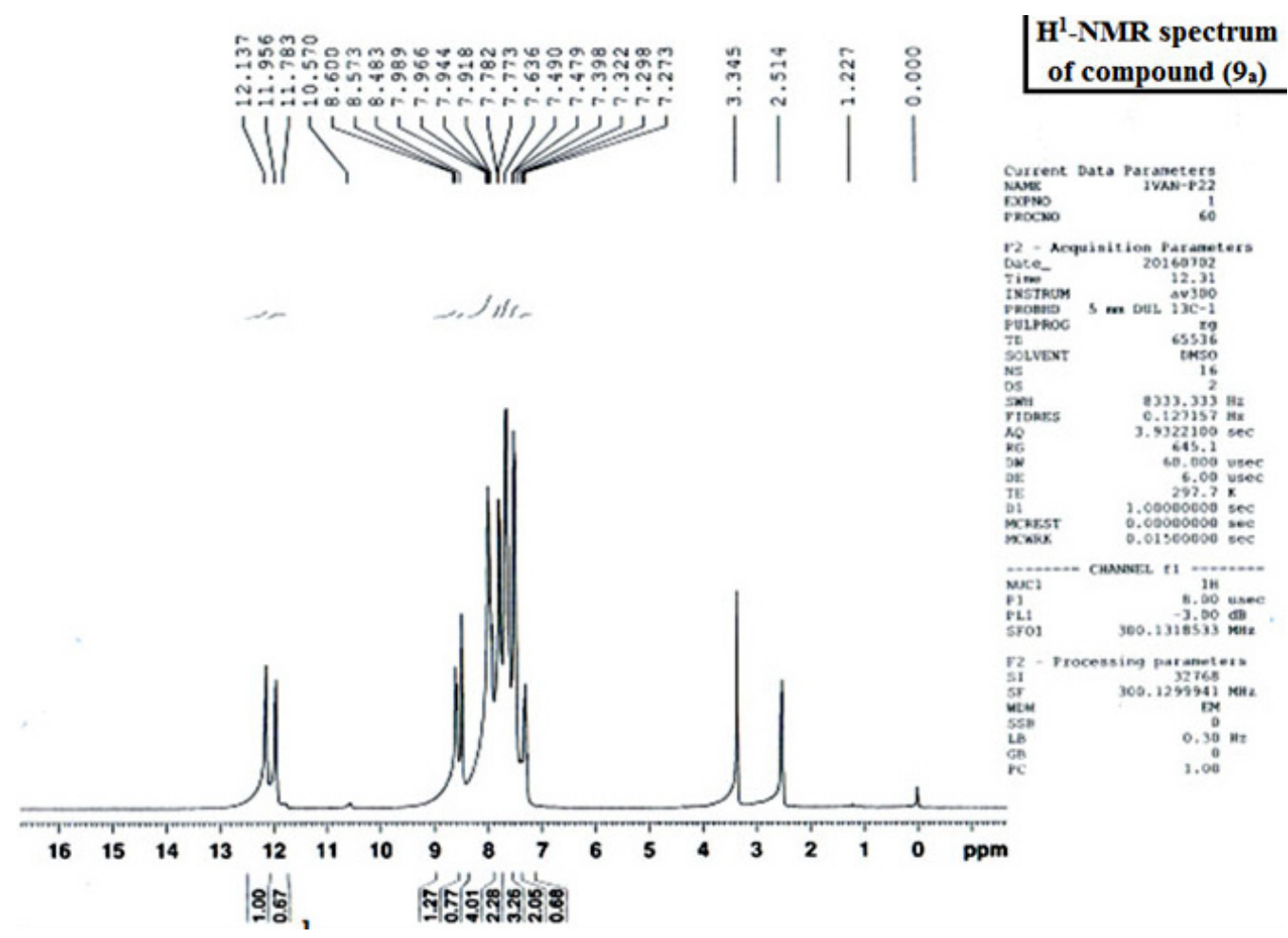

Fig. 6:

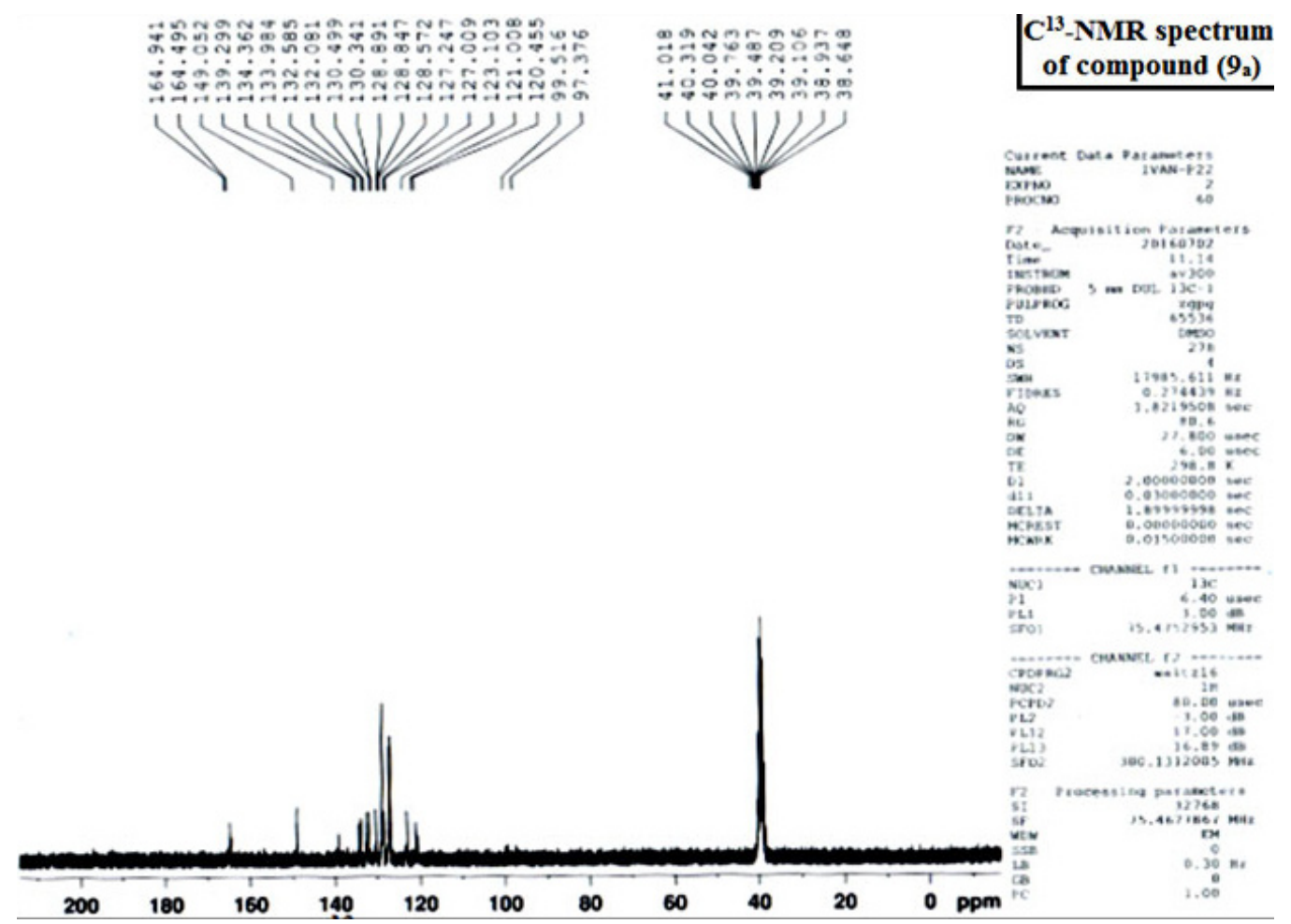

Fig. 7: 


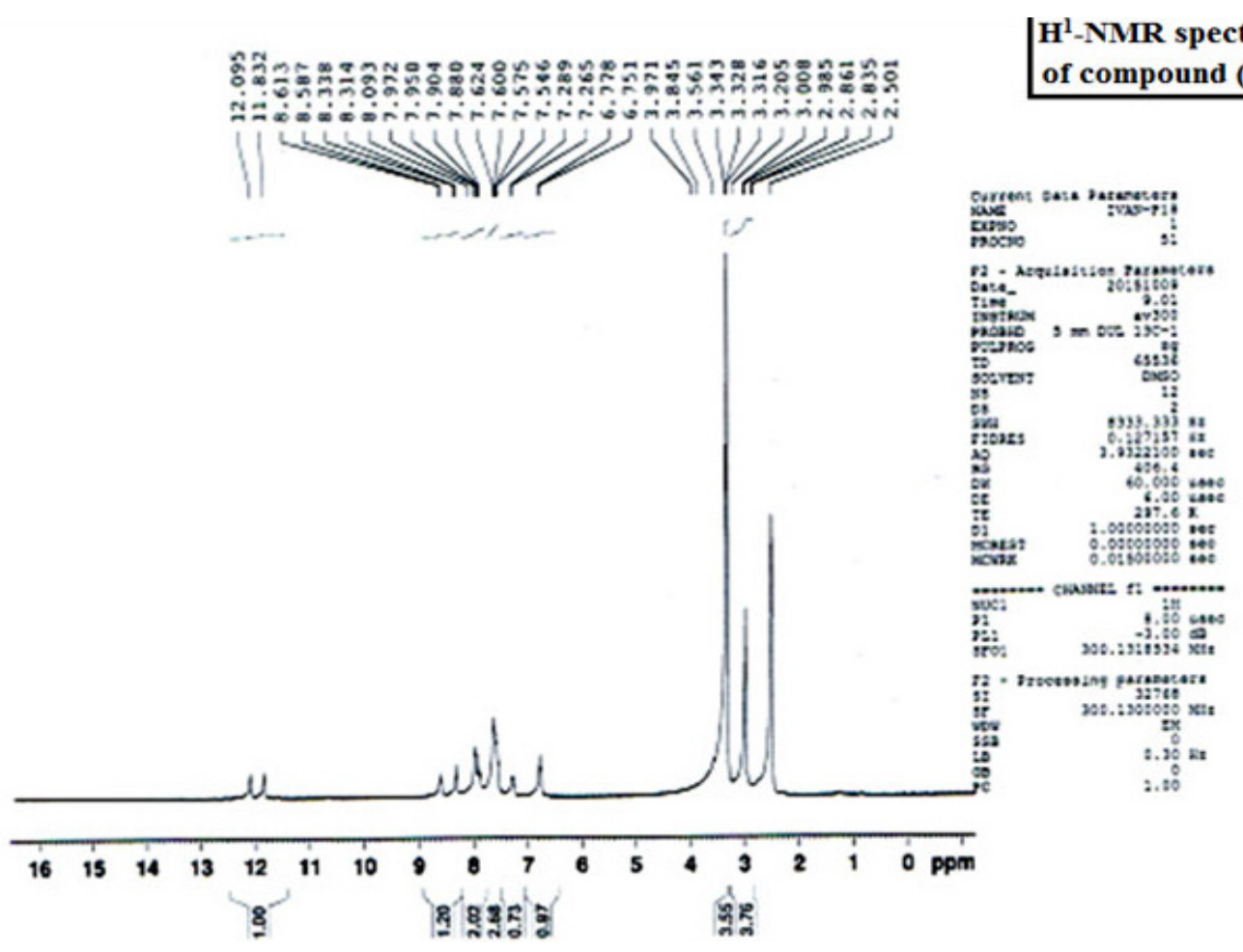

Fig. 8:

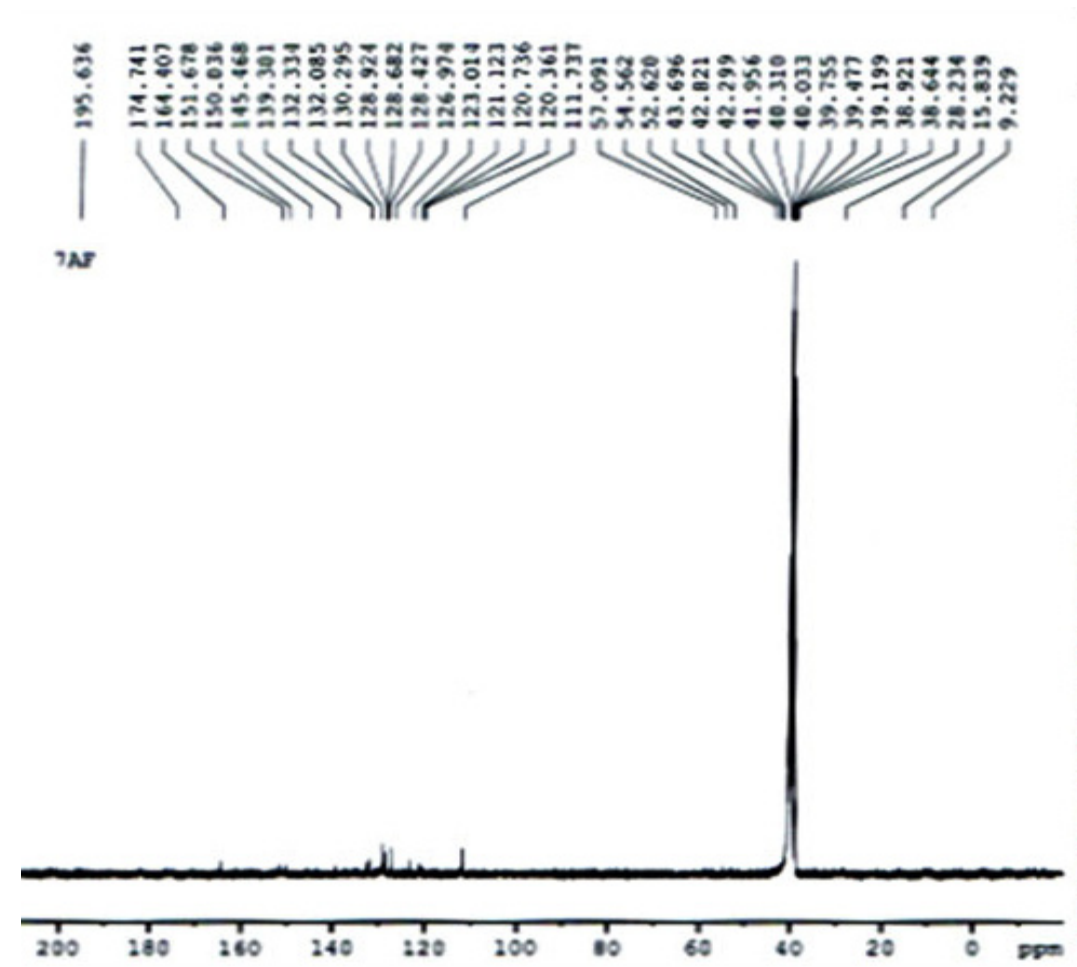

$C^{13}$-NMR spectrum

of compound $\left(10_{b}\right)$

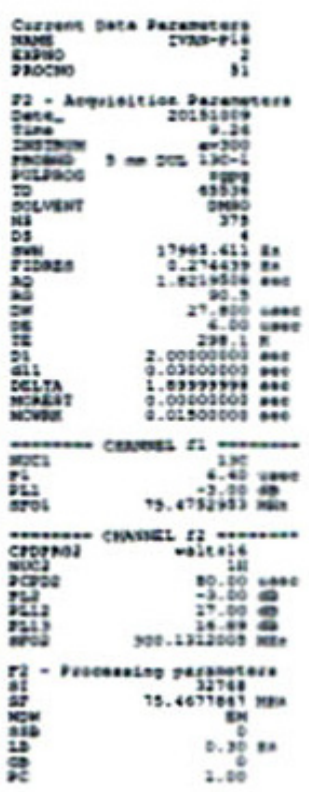

Fig. 9: 
Table 3 : Antibacterial activity of some synthezised compounds

\begin{tabular}{lcc}
\hline & Zone of inhibition & (mm) \\
\hline $\begin{array}{l}\text { Comp. } \\
\text { No. }\end{array}$ & Escherichia coli & $\begin{array}{c}\text { Staphylococcus } \\
\text { aureus }\end{array}$ \\
\hline 5 & 16 & 15 \\
6 & 25 & 25 \\
7 & 40 & 28 \\
8 & 14 & 16 \\
9 & 12 & 14 \\
\hline
\end{tabular}

cyclic tryptophan. Singlet signal at $\delta 4.38$ for $\mathrm{CH}$ of cyclic tryptophan.

Reaction of compound 6 with hydrazine hydrate in refluxing ethanol gave the corresponding compound7 The FTIR spectrum of compound 7 confirmed the presence of intense absorption bands at $3329,3105,1662$, and $1620 \mathrm{~cm}^{-1}$ due to amino, carbonyl amide and imine groups respectively. The ${ }^{1} \mathrm{H}$ NMR spectrum of compound 7, fig.(4), showed two signals, triplet signal at $\delta 3.44$ for $\mathrm{CH}$ proton and doublet signal at $\delta 2.68$ for proton of $\mathrm{CH}_{2}$ group. A singlet signal at $\delta 10.45$ for proton of $\mathrm{NH}$, a multiple signal at $\delta 7.18-8.20$ region related to aromatic protons, a signal at $\delta 8.40$ for proton of $\mathrm{NH}$ of tryptophan.

Compound 8 was synthesized by the condensation of compound 4 with phthalic anhydride in dry benzene. The chemical structure of this compound was determined by FTIR and ${ }^{1} \mathrm{H}$ NMR spectroscopic techniques. The recorded infrared spectrum of the compound depicts the disappearance of $v$ s and vas of $\mathrm{NH} 2$ group at $(3317,3165) \mathrm{cm}^{-1}$, the appearance of two bands $(1703,1786) \mathrm{cm}^{-1}$ for carbonyl group of cyclic amide, and a band rise at (1678) $\mathrm{cm}^{-1}$ due to carbonyl of amide. On the other hand, the proton-NMR spectrum of compound 8, fig. (5), shows many signals, a triplet at $\delta 3.59$ and a doublet at $\delta 1.19$ for $\mathrm{CH}$ and $\mathrm{CH}_{2}$ protons respectively, a singlet at $\delta 4.39$ for the tryptophan five membered ring $\mathrm{CH}$, two singlets at $\delta 11.76$ and $\delta 12.01$ for $\mathrm{NH}$ and $\mathrm{OH}$ protons in the two tautomeric forms, a multiple at $\delta 7.26-8.79$ for the aromatic protons, and a singlet at $\delta 9.65$ which corresponds to the tryptophan $\mathrm{NH}$ group.
Compound 4 condensed easily with different aldehydes in ethanol containing piperidine at reflux temperature affording the corresponding Schiffs bases compounds 9a-d. The FTIR spectrum of compounds 9a-d showed disappearance of amino group and exhibited peak at region (1604-1649) $\mathrm{cm}^{-1}$ belonging to $(\mathrm{C}=\mathrm{N})$ group. The ${ }^{1} \mathrm{H}$ NMR spectrum of compound 9a,fig.(6), showed singlet signals at $\delta 10.57,11.78,11.95$, and 12.13 corresponding to $\mathrm{CH}=\mathrm{N}, \mathrm{NH}$ of tryptophan, $\mathrm{NH}$ and $\mathrm{OH}$ protons in two tautomeric forms respectively. A multiple signals at $\delta 7.27-8.60$ region owing to aromatic protons. The ${ }^{13}$ CNMRspectrum of compound 9a,fig. (7), (DMSO): $\delta$ 123.10-132.58(benzene rings), (127.24,128.89) ppm due to two carbon of $\mathrm{C}=\mathrm{N}$ groups. While (164.49-164.94) ppm due to two carbonyls of amide groups.

Synthesis of compounds 10 a,b was carried out via condensation of compounds $9 \mathrm{a}$,b with phthalic anhydride in dry benzene. The purity structural formula ofcompounds10a,b were confirmed by FTIR and ${ }^{1} \mathrm{H},{ }^{13} \mathrm{C}$ NMR spectroscopic techniques. The FTIR of compounds10a,b showed a peak at (16641691) $\mathrm{cm}^{-1}$ belong to carbonyl of cyclic ester. The carbonyl absorption band of amide was observed at (1656-1691) $\mathrm{cm}^{-1}$. The ${ }^{1} \mathrm{H}-\mathrm{NMR}$ spectrum of compound $10 \mathrm{~b}$, fig. (8), display two singles at $\delta$ 11.83 and 12.09 for $\mathrm{NH}$ and $\mathrm{OH}$ protons in the two tautomeric forms, singlet at $\delta 8.61$ owing to protons of $\mathrm{NH}$ of tryptophan group, a multiple signal at $\delta$ $(6.75-8.58)$ region attributed to aromatic protons. Two signals, triplet signal at $3.32 \delta$ for $\mathrm{CH}$ proton and doublet signal at $2.86 \delta$ for protons of $\mathrm{CH}_{2}$ group, singlet signals at $3.84 \delta$ for $\mathrm{CH}$ of tryptophan. Singlet signal at $8.58 \delta$ for $(-\mathrm{CH}-\mathrm{O}-\mathrm{N})$ group. The ${ }^{13} \mathrm{C}$ NMR spectrum of compound 10b,fig.(9), (DMSO): $\delta 28.23$ $\left(\mathrm{CH}_{2}\right), 123.01-132.33$ (benzene rings), 164.40 (CO amide), 195.63 (CO of cyclic ester).

\section{Biological Activity}

In this study the antimicrobial activity of the synthesized phenyl quinazoline on two kinds of bacteria namely, staphylococcus aureous and Escherichia coli was investigated. Table (3) shows the antibacterial activity of some synthesized compounds and the obtained zones. Results shows that compound 7 exhibit highly antibacterial activity against Escherichia coliand Staphylococcus aureus than other compounds. 


\section{CONCLUSIONS}

A series of newly phenyl quinazoline compounds were successfully synthesized and characterized. Some of the newly compounds were tested for antibacterial activity which compound 7 exhibit highly antibacterial activity against Escherichia coli and Staphylococcus aureus than other compounds.

\section{ACKNOWLEDGEMENTS}

The author would like to thank the University of Baghdad for supporting this study and provide the grant for this study. We are also grateful to Dr. Zeinab M. Al Rubaei for her contributions.

\section{REFERENCES}

1. A. A. Nagar, A. Patel, K. S. Rajesh ,K. R. Danao, and L. G. Rathi, Pharmagene 2013. 1(2),49-53 .

2. J. Souad, B. L. Nabeel and M. B. Salah, Journal of Al-Nahrain University 2016,19 (1), 1-12 .

3. N.K.Sinha,A.J.Asnani,B.R.Dravyakar, Asain journal of pharmaceutical and clinical research 2013,6(3) .

4. W. Dan and G.Feng, Chemistry Central Journal 2013,7(95),1-15.

5. D.Mukherjee,A. Mukhopadhyay, K.B. Shridhara, A.M. Shridhara, K.S. Rao, International Journal of Pharmacy and Pharmaceutical Sciences 2014 , 6( 5),567571 .

6. $M \cdot K \cdot S r i v$ a $s t a v a d$ S.M.Shantakumar, Chemical Science Transaction. 2013, 2(3): 1056-1062 .

7. O.H.Abid and A.H.Ahmed, Inter J Appl Nat Sci. 2013,2,11-20 .

8. A.Shetha and I.A.Wijdan, J Chem Pharm Res. 2013,5,: 42-45 .

9. Zaranappa et al.,Int J Chem Tech Res. 2012,4, 1527-1533.

10. B.Pati .and S.Banerjee, J Adv Pharm Edu Res. 2013,3,136-151.

11. L.Wei, Z.Xiaotian, C.Yang,G. Shunmin ,T. Feifei Ba,Wei,Y.Chao ,W. Mingping, L.Yu,S.Yunlong, Z.Ju, Z.Weicheng, Z.Youjun, Z.Feng,G. Hao,Z.Canhui ,Tetrahedron 2016,72 (23), 3185-3192.
12. T. Shweta, M. Vikas, S. Vasudha, S. Pushplata , S. Manjul, Asian Journal of Pharmaceutical and Clinical Research 2012 , 5( 1),98-100 .

13. A. V. Danilov, Clinical Therapy 2013, 35,12581270 .

14. M.F. Ahmed and M.Youns, Archiv der Pharmazie. 2013,346,610-617 .

15. D.Kumar ,G.Mariappan ,A.Husain,J. Mongaand S.Kumar, Arabian J. Chem. 2014, 10,1016.

16. F.L.Farajet al.,Sci.WId J. 2014, 10,1155.

17. D. Gor,P. Patel, M.Shah, and S.Patel, Der Pharma Chemical 2012,4(2),626-628.

18. K.Faghihi, M.Nourbakhsh, and M.Hajibeygi, Journal of Saudi Chemical Society 2011,Inpress, xxx,:xxx-xxx.

19. M.S.Fouad, I.Redha, Al-Bayati, and Araa AlJuboori. , Al-Mustansiriya Journal of Science 2006, 17(3), 15-26.

20. A.H.Mekky, ,ph.D.Thesis, college of Science ,University of Al-Mustansiriya, 2015.

21. S.Cao ,X.Qian, G.Song. ,Q. Huang, Journal of Fluorine Chem. 2002, 117(1),63-66.

22. I. K. Jassim, S. A. Jabbar and A. Waaled, Karbala Journal of Parmaceutical Science 2015,10, 102.

23. M. Noolvi,S. Agrawal , H. Patel,A. Badiger, M. Gabaand A. Zambre, . Arabian Journal of Chemistry 2014,7(2),219-226.

24. R.W. Adam and E. H. Zimam, .Karbala Journal of Pharmaceutical Science 2014,7,195-207 